\title{
Inovações educacionais no tempo presente e rupturas no paradigma moderno: uma análise das pesquisas educacionais da Universidade de Genebra
}

Educational innovations at the present time and ruptures in the modern paradigm: an analysis of the educational research of the University of Geneva

\section{Les innovations éducatives du temps présent et les ruptures dans le paradigme moderne : une analyse de la recherche en éducation de l'Université de Genève}

\author{
Ednéia Regina Rossi*
}

\begin{abstract}
RESUMO
Os anos de 1990 têm se configurado como de deslocamento no modo de se pensar e de se organizar o trabalho escolar e a formação de professores. As mudanças estão associadas ao diagnóstico de que a escola está com dificuldade em manter um nível desejável de aprendizagem e que falha no papel de ensinar de forma eficaz a todos. Esse contexto de crise é, também, de processos de mudanças. Este estudo trata de inovações no campo do trabalho escolar e da formação de professores, a partir da produção e da experiência de pesquisadores do Laboratoire de Recherche Innovation, Formation, Éducation (LIFE) da Universidade de Genebra na Suíça. De cunho exploratório e qualitativo e utilizando a metodologia de análise de conteúdo
\end{abstract}

* Universidade Estadual de Maringá. Maringá, Paraná, Brasil. E-mail: errossi@uem.br https://orcid.org/0000-0002-7551-5397 
proposta por Bardin (1977), esta investigação foi guiada pelo questionamento: Do que tratam as produções do LIFE quando discutem a inovação das práticas pedagógicas e da formação de professores? Embora toda inovação envolva algum grau de dificuldade e de resistência, nem todas possuem o mesmo grau de reação, uma vez que podem operar em níveis de mudanças mais ou menos complexos. Enquanto há inovações que desejam tocar nas estruturas que definem a cultura da organização das instituições escolares, como o tempo e o espaço que estruturam o seu trabalho, outras operam no plano do próprio trabalho, como as metodologias e os materiais didáticos.

Palavras-chave: Inovações educacionais. Culturas escolares. Tempo presente. Universidade de Genebra na Suíça.

\begin{abstract}
The 1990s have been configured as a time of shift in the line of thought and of organizing schoolwork and teacher training. These changes are associated with the diagnosis that schools are having trouble to maintain a desirable level of learning and that they have failed in their role of teaching in an effective way for all. Such context of crisis is also of processes changing. This study brings about innovations in the field of schoolwork and teacher training from the production and experience of researchers at the Laboratoire de Recherche Innovation, Formation, Éducation (LIFE), in the University of Geneva, in Switzerland. Of exploratory and qualitative nature and utilizing the content analysis methodology as proposed by Bardin (1977), this study was guided by means of questioning: what do the productions of LIFE bring about when discussing innovation of pedagogical practices and teacher training? Despite all innovation having a degree of difficulty and resistance, not all possess the same level of reaction, since they can operate within different levels of change, being complex to different degrees. While certain innovations wish to reach the structures themselves, which define the organizational culture of schooling institutions such as the time and space that shape their work, others operate on the work itself, as methodologies and course material.
\end{abstract}

Keywords: Educational innovations. School cultures. Present time. University of Geneva in Switzerland.

\title{
RÉSUMÉ
}

Les années 1990 ont été configurées comme une période de déplacement dans la manière dont le travail scolaire et la formation des enseignants sont organisés et pensés. Ces changements sont associés au diagnostic selon lequel les écoles ont des difficultés à maintenir un niveau d'apprentissage souhaitable et qu'elles échouent dans leur rôle d'enseignement efficace 
pour tous. Ce contexte de crise est également un processus de changement. Cette étude traite des innovations dans le domaine du travail scolaire et de la formation des enseignants à partir de la production et de l'expérience des chercheurs du Laboratoire de Recherche Innovation, Formation, Éducation (LIFE) de l'Université de Genève en Suisse. De nature exploratoire et qualitative, et utilisant la méthodologie d'analyse de contenu proposée par Bardin (1977), cette investigation a été guidée par le questionnement : de quoi traitent les productions du LIFE lorsqu'elles traitent de l'innovation des pratiques pédagogiques et de la formation des enseignants ? Bien que chaque innovation implique un certain degré de difficulté et de résistance, toutes n'ont pas le même degré de réaction, car elles peuvent opérer à des niveaux de changement plus ou moins complexes. Si certaines innovations souhaitent toucher aux structures qui définissent la culture d'organisation des institutions scolaires, comme le temps et l'espace qui structurent leur travail, d'autres opèrent au niveau du travail lui-même, comme les méthodologies et le matériel pédagogique.

Mots clés: Innovations éducationnelles. Cultures scolaires. Temps présent. Université de Genève en Suisse.

\section{Introdução}

Caracterizados por implementações de mudanças nos sistemas de ensino de diferentes países, os anos de 1990 se configuram como um período de clivagem no campo educacional. Essas mudanças possuem contextos específicos de seus países e regiões, mas vêm amparadas em argumentos similares, como, por exemplo, os de que a escola tem dificuldade em manter um nível desejável de aprendizagem e que falha no papel de bem ensinar a todos, tendo a reprovação e a evasão como problemas a serem combatidos. Trata-se de um contexto de crise experienciado por diferentes países de cultura ocidental, embora em níveis de agravamento bastante diversos.

Se os contextos de crise são também processos de mudanças (RICOEUR, 1988), convém examinar o que foi produzido de novo no campo educacional em resposta aos problemas acima mencionados. Trata-se de apreender o aspecto dinâmico ou de produção de rupturas na realidade escolar, embora esse movimento não seja progressivo e linear e que, nele, também esteja presente o seu contrário, o movimento estático ou de permanência que trabalha no sentido de preservar o antigo modo. 
Produzir uma inteligibilidade para esse movimento de mudanças é um desafio para os pesquisadores em educação. Este artigo quer contribuir com esta construção por meio da análise da produção do Laboratoire de Recherche Innovation, Formation, Éducation (LIFE) ${ }^{1}$, vinculado à Faculdade de Ciências da Educação da Universidade de Genebra na Suíça. A escolha deste lugar é justificada por dois fatores principais. O primeiro é que o impacto de suas ideias teve capilaridade não apenas em Genebra ou em países francofônicos. Parte de sua produção foi traduzida para o português, o que favoreceu a sua divulgação em países lusófonos, particularmente o Brasil. A circulação desses conhecimentos exerceu influências em pesquisadores do campo educacional, em educadores e em políticas educacionais. $\mathrm{O}$ segundo diz respeito à peculiaridade no modo de apreensão do fenômeno de inovação escolar, feita em seu próprio movimento de construção, por meio da participação de seus pesquisadores em projetos de inovação escolar em Genebra. A abordagem da inovação, como definida por seus investigadores, é construtivista, interacionista e antropológica, tornando possível a observação do aspecto processual e social do fenômeno.

Genebra possui tradição histórica na aproximação entre a pesquisa educacional e o campo das práticas escolares, embora essa conduta possa ser observada em outros países, principalmente no que diz respeito à pesquisa e à formação de professores. Assim sendo, em Genebra, desde o início do século $\mathrm{XX}$, gestou-se uma cultura, tanto no campo educacional como no campo da pesquisa, vista como tributária do pensamento do filósofo alemão Immanuel Kant (1724-1804), de que se, de um lado, a experiência sem o conceito é cega, do outro, o conceito sem a experiência é vazio.

É deste lugar fortemente marcado pela tradição na cooperação entre pesquisas educacionais e práticas escolares que os pesquisadores da Universidade de Genebra, especialmente do LIFE, produziram conhecimentos sobre a inovação educacional no contexto de reformas de sistemas educacionais do final do século $\mathrm{XX}$, mobilizadas em vários países. Perguntar sobre o que tratam as produções do LIFE quando discutem a inovação das práticas pedagógicas e da formação de professores é uma maneira de contribuir com a produção de uma inteligibilidade sobre as inovações do campo educacional no tempo presente.

1 Pesquisa realizada durante o estágio pós-doutoral. Esse laboratório tem entre as suas preocupações a investigação sobre a inovação no campo da educação e da formação de professores. 


\section{A semântica da inovação}

Se, no tempo presente, tudo é temporário, como reflete Bauman (2001), e a metáfora da "liquidez" qualifica a experiência de uma vida social incapaz de manter uma forma; se suas instituições, crenças e estilos de vida mudam antes de se enraizarem e de solidificarem costumes e hábitos (BAUMAN, 2001) e se o ritmo frenético inaugura outra experiência com a temporalidade (ROSA, 2010), é preciso questionar se todas as mudanças obedecem a um mesmo ritmo e intensidade e se elas envolvem, na mesma proporção, as diferentes dimensões da vida social. Por outro lado, se tudo muda o tempo todo (HERÁCLITO, 1989), é preciso perguntar se a experiência e o significado de mudança são os mesmos em tempos e culturas diferentes.

O conceito de "inovação" no tempo presente possui uma singularidade em relação a outras temporalidades, sendo que um recuo no tempo se torna importante para melhor precisá-lo. O comportamento inovador em séculos anteriores, como o dos séculos XVI, XVII e XVIII, por exemplo, não era apenas desvalorizado, mas identificado como ameaçador. A ressignificação do conceito contemporâneo de inovação ocorreu ao longo de duzentos anos e, no século XX, a inovação se tornou uma palavra-chave e esteve presente tanto em discursos públicos de governantes como em formulações teóricas de diferentes campos de conhecimento, como história, psicologia, sociologia, economia, antropologia, educação, política e administração. O que outrora foi chamado de mudança e modernização torna-se inovação, inaugurando um significado completamente novo ao termo (GODIN, 2015).

A análise das alterações do campo semântico do termo "inovação" auxilia na especificação de seu significado no tempo presente. Durante o período moderno, a inovação era remetida a cinco conceitos. O conceito de "mudança", que era visto como um processo natural e desencadeado por vontade divina e socialmente aceito; os conceitos de "reforma" e "renovação", também mais aceitos, que eram entendidos como intencionais, contudo, realizados de forma gradual e baseados no que já existia; a "inovação" e a "revolução", igualmente compreendidas como processos intencionais, que provocam ruptura com a prática existente, podendo ser radicais, violentas e totais, por isso não desejadas. No entanto, o campo semântico da "inovação", no transcorrer do século XX, foi alterado. A inovação passou a ser entendida como mudança intencional e planejada, a qual exige estratégia e investimento. Ela mantém a ideia de revolução enquanto um impacto na sociedade, contudo, além de passar a ser desejada, uma nova semântica surgiu. A inovação passa a ser utilizada em três 
sentidos: como "diferença", porque inaugura uma novidade; como "criatividade", porque combina ou recompõe ideias ou coisas de uma nova maneira, e como "originalidade", por iniciar uma prática inédita (GODIN, 2015).

A nova abordagem do vocabulário se insere na rede de sentidos e torna possível identificar a criatividade com um significado diferenciado, próprio do contexto do final do século XX. Não é à toa que a escola de educação básica francesa estabeleceu a criatividade como um princípio de formação que desejava formar para que todos fossem capazes de modificar a cultura herdada, ressignificando-a para si e seu contexto, como demonstram os estudos de $\mathrm{Li}$ e Maulini (2016). O sentido da inovação como criatividade é uma essência socialmente desejada no final do século XX e que a escola, mas não apenas ela, deseja desenvolver.

A esses significados do tempo presente, agrega-se, ainda, uma dimensão conceitual, a partir da qual se entende que nem toda novidade é uma inovação. A invenção, embora seja uma novidade, não diz respeito ao processo de colocar algo em funcionamento no meio social, ao contrário, a "inovação é a aplicação de ideias, invenções e ciência" (GODIN, 2015, p. 24, tradução nossa). Assim, a inovação é o movimento de utilização prática de algo. Logo, ela toca nas estruturas sociais estabelecidas, podendo apresentar um conflito com a ordem e seus defensores, tornando seu sucesso incerto. Assim, a natureza da inovação é compreendida como processual, uma vez que a apropriação da novidade jamais ocorre de forma total, imediata e definitiva pela sociedade (GODIN, 2015; ALTER, 2010). Os sujeitos realizam escolhas, adaptam, fazem bricolagem, utilizam e depois desistem, tudo varia em função de inúmeras situações, algumas previstas, outras não. Pode-se dizer que a inovação é mais que um processo, "é a história de um estado de tensão permanente entre as possibilidades representadas pela invenção e as escolhas coletivas que são progressivamente tomadas a partir dela" (ALTER, 2010, p. 14, tradução nossa).

O que mobiliza um processo inovador se associa a um outro conceito: o de "utilidade", compreendido em termos de "modernização", de "avanço" e de "desenvolvimento". No campo econômico, o conceito vem associado a "crescimento", "produtividade", "competitividade" e "lucros". No campo das organizações, está relacionado à "eficiência". No campo social, vem relacionado às "necessidades" (GODIN, 2015, p. 25). Assim, no campo da educação escolar, pode-se dizer que a inovação se associa tanto às necessidades quanto à eficiência. 


\section{A problemática da inovação em educação}

Um processo de inovação não se inicia por um modismo, mas se vincula à necessidade de readequar a escola à sua função social (MAULINI, 1997; PERRENOUD, 1995). Embora este fenômeno ocorra, traduzir a inovação em um objeto de pesquisa no campo da educação é complexo.

No campo da educação, o que se considera inovação pode não ser uma novidade no sentido real de sua existência, mas no sentido relativo de quem a utiliza, ou seja, num sentido antropológico de que é uma inovação para o grupo envolvido no processo (CROS, 1997; GODIN, 2015). Por outro lado, estudos históricos americanos sobre inovações educacionais identificam que elas se configuram como um reinventar de movimentos antigos (PERRENOUD, 1995). Da mesma maneira que ideias lançadas como novas no momento presente, foram ideias e sonhos de gerações passadas que resistiram na realidade, seja por meio das instituições, dos professores, dos estudantes, das famílias, da administração ou de políticas (PERRENOUD, 2002). Se se trata de uma recriação, num movimento de reformulação do passado, então, é preciso se perguntar o que existe do tempo presente nisso tudo, o que há de inédito que cria um outro sentido e que transforma o já existente em algo não apenas diferente, mas novo.

No campo educacional, o termo "inovação" é relacionado a vários conceitos e pode se referir tanto ao microespaço de um estabelecimento escolar, como abranger o sistema de ensino de um estado ou país. Os termos "mudança", "reforma" e "renovação" são amplamente usados na literatura analisada. As palavras "mudança" e "inovação" são utilizadas para se referir a fenômenos diversos, tanto do macro como do microespaço. Por outro lado, o termo "reforma", em geral, é utilizado para fazer referência a uma mudança operada no nível do sistema educacional ou de um subsistema. Trata-se de um ato político e intencional, sendo incomum o termo fazer referência a mudanças operadas em um estabelecimento ou em uma sala de aula. Ao contrário, o conceito de "renovação" faz referência a uma mudança local e com frequência contínua. Trata-se de mudanças que se processam na vida de um estabelecimento de ensino ou em práticas de uma sala de aula: "a renovação faz parte da própria natureza dos sistemas vivos e, portanto, também dos estabelecimentos de ensino" (PERRENOUD, 1999, tradução nossa).

A escola pertence ao conjunto de instituições que possui seu enraizamento na tradição. Contudo, como lugar de formação e de preparação dos indivíduos para a vida em sociedade, dela também se espera um movimento de mudança 
e de novidade. A escola vive essa ambiguidade de guardiã da tradição e de partícipe da mudança (CROS, 1997). Pode-se identificar "a existência de uma concorrência entre a lógica da inovação, que implica aceitar a incerteza dos meios e dos fins, e a lógica da organização, que pressupõe, ao contrário, conseguir erradicar a incerteza através do planejamento, programação e padronização" (ALTER, 2010, p. 3, tradução nossa). Assim, as instituições escolares mudam, mas preservando uma identidade, uma estrutura, uma cultura, mesmo quando os atores se renovam. A ruptura e a continuidade são lados de uma mesma realidade. A complexidade dos processos de inovação exige uma análise que se distancia de simplificações e de representações que polarizem, de um lado, a tradição como obsoleta e medíocre e, do outro, a inovação como sinônimo de superação do conformismo e sucesso seguro. Uma inovação nem sempre significa melhorar o mundo, a exemplo do nazismo e da bomba atômica, que foram inovações em suas épocas. Assim, tudo depende dos contextos culturais, dos valores em jogo, dos ideais produzidos e validados pela coletividade (MAULINI, 1997).

A fim de identificar padrões comuns observáveis no fenômeno de inovação escolar no tempo presente, procurou-se examinar as produções do LIFE sobre o tema, particularmente, no que diz respeito às mudanças nas práticas pedagógicas e na formação de professores.

\section{Aspectos metodológicos}

Para selecionar o corpus documental de análise, procedeu-se à coleta das produções do LIFE a partir do repositório on-line do laboratório, bem como das páginas on-line dos seus pesquisadores responsáveis. Para seleção do material, adotou-se como primeiro critério que o título da produção incluísse uma ou mais das palavras-chave: "inovação"; "renovação"; "nova(s)"; "transformação"; "evolução"; "mudança"; "criatividade" e "reforma". Assim, a seleção inicial ocorreu pela leitura dos títulos, sendo descartados aqueles que não possuíam as palavras-chave definidas e mencionadas anteriormente. Após a aplicação desse primeiro filtro, foram encontradas 99 produções.

Das produções encontradas, para integrar o presente estudo, elas deveriam preencher os seguintes critérios: a) ser artigos científicos ou profissionais, ou capítulos de livros, ou notas críticas, podendo ser divulgados em revistas 
científicas ou não, no jornal ou no website da Universidade de Genebra²; b) que o fenômeno analisado correspondesse ao contexto da educação básica; c) que a abordagem fosse referente às práticas pedagógicas, mas sem especificar uma disciplina em particular, ou às políticas educacionais implementadas, ou ao trabalho de diretores, gestores e professores; d) que os estudos analisassem contextos a partir de 1990; e) que a data de publicação da produção ocorresse entre os anos de 1990 a 2019.

Para o refinamento das produções potencialmente elegíveis, além da leitura dos títulos, foi realizada uma "leitura flutuante" que incluiu os resumos, a introdução e as considerações finais. Excluíram-se, após essa leitura, as referências duplicadas e os artigos que não se enquadravam nos critérios estabelecidos e explicitados anteriormente. Após a aplicação desses critérios, restaram 74 produções que compuseram o corpus documental da pesquisa e que foram analisadas na íntegra.

Para a análise da documentação, aplicou-se a metodologia de análise de conteúdo de Bardin (1977), sendo os conteúdos codificados e posteriormente agrupados em categorias para discussão e análise. Os resultados serão apresentados a seguir.

\section{Rupturas em práticas e em conceitos no campo da educação escolar no tempo presente}

A análise do conjunto das produções permitiu propor uma classificação de suas abordagens em quatro grandes eixos de inovação, que podem se desdobrar em subclassificações se se considerar o objeto específico abordado, sendo eles: as práticas e teorias pedagógicas, a profissionalização de professores e diretores, a gestão das instituições escolares e a forma dos sistemas de ensino operarem. É importante considerar que a gestão da inovação educacional no âmbito das instituições escolares foi um tema tratado pelos pesquisadores que

2 As publicações do LIFE não se limitam às revistas científicas, outros meios de divulgação são utilizados, em que se estabelecem diálogos com públicos não acadêmicos e revela-se a identidade do grupo. Eles operam na prática da pesquisa com o conceito de cooperação debatido teoricamente. As pesquisas se caracterizam por uma cooperação entre pesquisadores e profissionais do terreno que ocupam lugares diferentes no sistema educacional de Genebra, desenvolvendo um processo de trabalho que expande e fortalece o conhecimento de todos os envolvidos. 
acompanharam o processo de implantação da reforma educacional na década de 1990. No entanto, neste artigo, priorizou-se a apresentação dos resultados relativos aos dois primeiros eixos mencionados acima.

\section{O campo pedagógico: concepções, práticas e organização do trabalho}

Agregam-se nesta categoria as inovações do campo pedagógico, ou seja, tudo o que afeta a estrutura das práticas educativas, como, por exemplo, teorias e concepções pedagógicas, didáticas e práticas de ensino, currículo, organização do trabalho pedagógico e avaliação.

No terreno das concepções pedagógicas, identifica-se uma retomada de vertentes da escola nova. A centralidade do aluno no processo de ensinoaprendizagem é recolocada a partir da intenção de se construir uma "pedagogia diferenciada" como alternativa de superação de um procedimento de ensino uniformizante. A escola democratizada é uma escola com públicos e demandas muito diferentes, ignorar essa realidade seria aumentar as desigualdades. Assim é definido o seguinte princípio:

Pedagogias diferenciadas: para um mesmo objetivo, as rotas podem variar, as aprendizagens podem ser orientadas de acordo com os efeitos do treinamento e da diferença restante entre o que é adquirido e o que resta a ser trabalhado. Módulos e ciclos de aprendizagem permitem individualizar os percursos e buscar para cada aluno recursos apropriados (MAULINI; PERRENOUD, 2005, p. 164, tradução nossa).

Para um mesmo objetivo, caminhos diferentes. A pedagogia diferenciada é uma nova mentalidade educacional aberta às possibilidades e à construção de uma prática de ensino e aprendizagem inexistentes. Ela se traduz pela organização do currículo e pela gestão de sala de aula fundamentadas a partir do uso de diferentes estratégias de ensino, bem como de diferentes tempos para a aprendizagem.

Seja sob o nome de pedagogias cooperativas, pedagogias institucionais, pedagogias centradas na pessoa, escola ativa, pedagogia interativa, abordagem de projetos, entre outras, o fato é que princípios defendidos pelas escolas novas foram revistos por propostas educacionais nas últimas décadas do século $\mathrm{XX}$ 
e início do XXI. Educadores, sociólogos e psicólogos de diferentes países revisitaram os princípios de uma pedagogia orientada para o aluno, desafiados pelo contexto que democratizou o acesso à escola básica e que atingiu patamares de inclusão significativa, abrangendo a quase totalidade, senão a totalidade, de crianças em idade escolar. Esses alunos não possuem "o mesmo nível de desenvolvimento, o mesmo capital cultural e linguístico, os mesmos recursos e atitudes, os mesmos ritmos de aprendizado" (PERRENOUD, 1991, tradução nossa), e, portanto, não conseguem aproveitar, de maneira similar, uma ação educacional uniforme. As novas pedagogias são fortemente convocadas a se oporem à escola que seleciona por meio da exclusão do diferente. Trata-se de uma outra maneira de observar as particularidades ou as individualidades, outrora defendidas pela escola nova. Embora não se exclua o seu sentido psicológico original, elas se associam ao debate dos direitos humanos e da justiça social. $\mathrm{O}$ princípio motriz do aluno como ator e não apenas como consumidor no processo ensino-aprendizagem é mantido. Contudo, o princípio do aluno ativo parece agregar um outro significado. A participação ganha outro sentido. Se, no início do século XX, o aluno era convocado a participar por meio da experiência e reproduzia a mesma lógica do conhecimento consolidado e transmitido pela escola, nesse final de século, o aluno é desafiado a recompor ideias de uma nova maneira. $\mathrm{O}$ desenvolvimento de habilidades exige a participação ativa do aluno num outro nível, numa experiência que saiba não apenas dominar o conhecimento existente, mas traduzi-lo em um saber-fazer ou significá-lo para o contexto em que vive. A participação ativa ganha uma dimensão na relação com os saberes acumulados, e nesse nível o aluno se engajaria na experiência coletiva de atribuir um novo sentido ao conhecimento existente.

Embora a diferenciação nos processos de aprendizagem signifique uma inovação, verifica-se que a escola, mesmo organizada na forma tradicional de agrupamentos uniformes e em classes homogêneas, já identificou a necessidade de trabalhar as diferenças no aprendizado. $\mathrm{O}$ apoio pedagógico é uma faceta da ação educacional diversificada e é uma estratégia real da escola, embora se mantenha a mesma lógica de organização do trabalho existente e se faça uma intervenção localizada e sem continuidade (PERRENOUD, 1991).

Ainda que a pedagogia diferenciada considere as necessidades diferentes dos alunos para produzir melhor inclusão e igualdade, tanto a pesquisa como a experiência têm assinalado que a diferenciação pouco compreendida pode agravar o que se deseja compensar, uma vez que a diferenciação não significa congelar o destino do aluno no nível em que ele se encontra, mas ultrapassá-lo (MAULINI, 2014). "Diferenciar não é respeitar o ritmo de cada pessoa", mas oferecer situações mais indicadas para fazê-lo avançar (PERRENOUD, 1998, tradução nossa). Tudo sugere uma abordagem complexa, capaz de colocar 
a diversidade dos alunos no centro da ação pedagógica, mas sem deixar de compartilhar significados e experiências comuns, flexibilizando estratégias e tempo, mas sem mascarar as dificuldades dos alunos. Concentrar esforços no que for necessário, sem causar mais discriminação.

Quais seriam os dispositivos colocados em jogo na implementação da pedagogia diferenciada? Com uma maior temporalidade, a organização do ensino em ciclos foi introduzida e rompeu com a lógica de graus anuais em favor de um aprendizado de longo prazo, estruturado a partir de objetivos e que manteve o princípio de expansão e superação entre eles. A reprovação convencional foi eliminada e definiram-se procedimentos para a passagem entre os ciclos, amparada em objetivos delineados.

No caso de Genebra, a organização do trabalho pedagógico procurou romper com o isolamento do trabalho docente e se desenvolveu a partir do trabalho em equipe e com gestão conjunta dos alunos. Vários professores poderiam trabalhar juntos para atender um grupo grande de estudantes, com recursos e desempenhando papéis diferenciados. Parte do programa de ensino organizouse pela arquitetura modular e alternava grupos de projetos ou de necessidades, como, por exemplo, quando necessário, um grupo se organizava com poucos alunos para possibilitar o atendimento de dificuldades mais específicas, enquanto um outro professor liderava uma oficina ou uma abordagem de projeto que, pelo seu caráter, acontecia com um maior número de alunos, pois exigia um outro tipo de interação na relação ensino-aprendizagem (GATHER THURLER, 1998a; MAULINI, 2000; PERRENOUD, 1995). Os módulos de aprendizado foram distribuídos ao longo do ano, com duração aproximada de vinte horas cada e organizados em duas ou três semanas. Neles, a matrícula ocorria de acordo com as necessidades e/ou habilidades, independentemente da idade ou do nível do aluno. Os projetos foram desenvolvidos em equipe, centrados em objetivos específicos, como, por exemplo, a correspondência grafo-fonológica ou a argumentação oral, sendo liderados por um dos professores. O tempo de ensino aproximava-se ao tempo de aprendizagem, em que cada aluno caminhava de maneira singular e não linear durante o ciclo (WANDFLUH; MAULINI, 2011).

O princípio de individualizar percursos não significou abandonar o trabalho em grupo. A ideia é que o trabalho fosse realizado em grupo, mas cada aluno passando de grupo em grupo, de uma situação de aprendizado para outra, de acordo com sua própria trajetória. Se, por um lado, o trabalho coletivo possibilita o aprendizado por meio das interações, princípio amplamente defendido pela psicologia sociocognitiva, por outro, a organização do trabalho no modelo graduado produziu a padronização didática no ensino por meio do estabelecimento das classes e suas hierarquias. Tudo sugere crer que não se trata de abandonar o agrupamento, mas de reinventá-lo organizando-o de outra maneira. 
Nessa direção, a inovação reside numa outra organização do trabalho pedagógico produzida sob uma estrutura de tempo e espaço diferentes. Trata-se de uma mudança na organização da classe tradicional de turmas fechadas e estáveis, com um professor responsável pela turma ou matérias, desenvolvendo seu programa anual e progredindo por meio de avaliação na escala e sucessão de graus de estudo. A questão é recompor os espaços e o tempo de formação, seja com grupos de várias faixas etárias, com flexibilização das fronteiras das turmas, ou com a organização de grupos que atendam a outras lógicas e necessidades, como as realizadas na organização por ciclos de aprendizado.

$\mathrm{Na}$ implantação dos ciclos de aprendizagem, as diversas realidades locais levaram as equipes de ensino a projetar e executar modelos de organização diferentes. Algumas escolas avançaram numa organização modular que requereu cooperação profissional avançada, enquanto outras mantiveram o agrupamento tradicional em classes estáveis. A organização do trabalho por grupos de necessidades, por grupos de nível, pela junção de classes, trabalhos em "duplas" ou em "trios"; turmas multietárias, ciclos com tempos diferentes - dois anos, quatro anos, oito anos ou nenhum - foram alternativas desenvolvidas (GATHER THURLER, 2000).

A estruturação do currículo em ciclos de aprendizado plurianuais ganhou espaço em sistemas educacionais, tanto no nível primário quanto no secundário, embora seu avanço seja lento e incerto. Sistemas educacionais, como o do Quebec, o da França e o da Bélgica, introduziram os ciclos, iniciando uma reestruturação na organização por programas anuais e nos grupos de classe tradicionais. A educação primária francesa, desde a lei de 1989, implantou os ciclos de aprendizagem com o princípio de mudança de professor no final do ano letivo, mas sem repetir de ano e desenvolvendo um trabalho em equipe em busca dos objetivos de final de ciclo. $\mathrm{O}$ ano letivo continuou a longa unidade em que se pontua o tempo escolar, sendo comum o estabelecimento de metas para o final do ano e fazer seu balanço. Observa-se que os ciclos não são regidos apenas por objetivos de final de ciclo, mas por estruturação em estágios intermediários, como trimestral, semestral, anual e outros. Identifica-se, ainda, que, na prática, a turma continuou a ser o grupo de referência, mas cuja constituição e disposição para o trabalho rompeu com a distribuição tradicional (PERRENOUD, 1999).

No contexto dessas discussões, a avaliação formativa é um dos elementos que acompanhou a mudança. Embora esse princípio não seja novo, nos contextos de inovação que eliminaram a reprovação tradicional, ela se aliaria à gestão de sala de aula, pois permitiria identificar as dificuldades, diferenciar as intervenções e individualizar a aprendizagem. 
A inovação coloca-se na direção de repensar a organização do tempo e do espaço escolares e suas lógicas fixas de ensino e de aprendizado. Organizações mais maleáveis e adaptáveis se apresentaram como alternativas, embora a força institucional da tradição escolar e das expectativas sociais tenha se imposto quer pelos sujeitos do interior ou do exterior da escola. Embora existam diferentes fatores que influenciam e definem as práticas escolares, o tempo e o espaço, por orientarem e permitirem a reprodução da escola, pertencem à base estruturante do trabalho, diferentemente, por exemplo, dos procedimentos didáticos ou do uso de materiais pedagógicos, que possuem maior maleabilidade e aceitação de mudança. Mesmo que eles modifiquem a realidade de sala de aula, pouco afetam a base sob a qual se estrutura o funcionamento do trabalho escolar.

No campo mais permeável da cultura escolar, a estratégia didática do questionamento é recolocada no cenário de debates sobre a produção de mudanças nas interações do processo de aprendizagem. Embora se reconheça a validade do questionamento a priori do mestre, esta não é a questão primordial. Trata-se de identificar, por meio de um jogo interativo de valorização das intervenções, a validade dos argumentos e o equilíbrio das relações de força entre os sujeitos do questionamento (MAULINI, 2004).

Com relação às inovações no campo das práticas pedagógicas, é relevante destacar que não se identificou nenhuma produção sobre o uso das tecnologias no material selecionado para a pesquisa, embora o debate esteja feito em outras produções do LIFE. Decidiu-se inseri-la aqui por considerar que a inovação técnica é um tema recorrente na literatura educacional e a sua abordagem é de interesse no contexto das inovações escolares.

As tecnologias da informação e comunicação (TIC) na escola são compreendidas como uma ferramenta de trabalho que acompanha a história das práticas escolares e dos materiais didáticos. Do uso do papel à utilização da internet as invenções vão se sucedendo e provocando o encontro entre a técnica e a instituição escolar. Maulini (2002) lembra que o impacto desse encontro não é unilateral: ao se apropriar das tecnologias, a escola transforma as suas práticas e também a tecnologia. As transformações ocorreriam ao menos em duas situações: quando as aplicações simulam as práticas de ensino ou quando são feitas adaptações das tecnologias existentes às necessidades das instituições (MAULINI, 2002). Contudo, importa menos o número de equipamentos e conexões disponíveis do que a relação dos professores e da escola com o mundo da ciência e da tecnologia. Trata-se de uma postura que entende as tecnologias, novas ou antigas, como parte da cultura humana, assim como são os outros domínios da cultura e do conhecimento (MAULINI, 2017). 


\section{O campo profissional: o coração da inovação em educação}

No contexto de final do século XX, discursos, tanto de organismos supranacionais e econômicos como de autoridades e profissionais de ensino, aumentam a relação estabelecida entre a eficiência dos sistemas educacionais e a profissionalização de professores e diretores. Essa visão, embora não concretizada em sua plenitude, corresponde aos princípios da gestão pública do ensino em vigor em vários países ocidentais e busca uma renovação dos estabelecimentos de ensino, aproximando-os de uma visão organizacional. Essa renovação traz o princípio da transformação do sistema educacional em inúmeros subsistemas, no sentido de se voltar às especificidades locais e garantir o envolvimento cooperativo da comunidade em torno de uma causa comum. Nesse cenário, os diferentes sujeitos assumem corresponsabilidade pela mudança (GATHER THURLER, 1998a).

O profissional é visto como o motor da inovação. Espera-se que ele saiba quais problemas precisará enfrentar e que proponha encontrar novos recursos para isso. A profissionalização docente é compreendida como a melhor estratégia para alavancar a modernização do sistema educacional. Nessa direção, o novo paradigma pretende deslocar a atenção da realização de reformas educacionais para o investimento na crescente profissionalização dos profissionais da educação.

\section{Profissionalização dos professores}

Os documentos analisados permitem identificar que a profissão docente, no contexto das demandas de nosso tempo, transita entre exigências complexas como: trabalhar em equipe, mas exercitar a individualidade e fazer as escolhas que o exercício profissional requer; ensinar para um grupo de alunos, porém individualizando o ensino; manter a legitimidade da escola, contudo considerar as famílias e a sociedade. Nesse contexto, testemunha-se uma reorganização gradual das habilidades profissionais do professor que envolve dominar o conhecimento específico a ser ensinado e os elementos que dizem respeito ao ensino, como a transposição pedagógica e o trabalho na escola. As novas habilidades são definidas em dez itens: 
1. Organize e facilite as situações de aprendizagem; 2. Gerencie a progressão da aprendizagem; 3. Projete e desenvolva sistemas de diferenciação; 4. Envolva os alunos na aprendizagem e no trabalho; 5. Trabalhe em equipe; 6 . Participe da administração da escola; 7. Informe e envolva os pais; 8. Use novas tecnologias; 9. Confronte os deveres e os dilemas éticos da profissão; 10 . Gerencie sua própria educação continuada (PERRENOUD, 2001, p. 8-12).

Por outro lado, o caminho pensado para a formação continuada seria outro. Ele estaria muito mais próximo de conhecimentos e habilidades desenvolvidos no próprio terreno das práticas do que de cursos esporádicos oferecidos por especialistas, embora se reconheça a importância desse tipo de formação em momentos pontuais. O princípio é o de que desenvolver a autoridade e o empoderamento profissional levaria à autonomia de escolhas e de definições exigidas pelo contexto. O que se deseja é que o profissional e sua prática deem respostas à complexidade de seu contexto de trabalho. $\mathrm{O}$ conhecimento capaz de transformar a realidade local não pode ser fornecido por um treinamento pronto, ele mantém relação com o desenvolvimento pessoal e o trabalho coletivo dos professores. Nessa direção, as salas de aula não são locais de aplicação de resultados, mas locais de pesquisa e de desenvolvimento de conhecimentos.

Perrenoud (1996) compreende esse contexto de demandas como de redefinição da identidade profissional. $\mathrm{O}$ conceito de profissionalização se constrói na oposição do que será chamado de proletarização da profissão dos professores. No modelo vigente, o trabalho do professor se vincularia à execução de um trabalho prescrito por autoridades, com pouca ou nenhuma autonomia do praticante. A proletarização aqui faz referência a um tipo de desapropriação simbólica (PERRENOUD, 1996; GATHER THURLER, 2004). Nesse modelo, estimula-se, por um lado, o isolamento e a competição entre os sujeitos, que são incentivados a focar o resultado individual de seu trabalho e, por outro, o refinamento da divisão do trabalho, que isola cada unidade da força de trabalho em seu próprio universo. A profissionalização, nesse final de século, procuraria uma outra via. A ideia é a de empoderamento dos profissionais, o que Gather Thurler (2004) concebe como um "exercício profissional de pleno direito". Nesse novo paradigma, ganhariam autonomia para escolhas de métodos e procedimentos e assumiriam responsabilidades de melhor desenvolvimento do currículo e da aprendizagem. O princípio seria reinventar o próprio trabalho, procurar soluções para novos problemas, adaptar métodos, ressignificar conteúdos, portanto, inovar. Contudo, trata-se de um modelo em construção e ele requer tempo e investimento. 
A promoção de tal profissionalização caberia ao poder público do sistema, mas, igualmente, diria respeito a todos os envolvidos. Trata-se de assumir a responsabilidade individual pelo compromisso coletivo. O exercício profissional requereria

[...] identificar e resolver problemas complexos; inventar estratégias e abordagens quando necessário; negociar planos de ação e uma divisão do trabalho dentro da organização escolar; refletir sobre sua prática, transformá-la; gerenciar sua educação continuada de forma independente; assumir a dimensão ética da profissão; controlar ansiedades, emoções e humores e administrar conflitos; assumir suas responsabilidades sem se refugiar atrás do sistema; cooperar sabiamente, trabalhar em equipe (GATHER THURLER, 1996, tradução nossa).

A nova identidade profissional alia desenvolvimento pessoal ao coletivo, o que Gather Thurler (1996) descreve como "prática cooperativa". Entre outras profissões, é comum o compartilhamento de conhecimento baseado na experiência coletiva, e se avançarem a partir do existente, a pesquisa científica e as técnicas de agricultura seriam exemplos disso. Contudo, o mundo educacional não funciona assim. Numa abordagem cooperativa, os problemas da escola $\mathrm{e}$ o aprendizado do aluno dizem respeito ao conjunto dos sujeitos envolvidos. Entende-se que a construção de soluções requer o confronto de estratégias, abordagens, técnicas e modelos. O trabalho coletivo representa um caminho para avançar em direção à profissionalização, embora sua construção não seja simples (GATHER THURLER, 1996).

A profissionalização é mais um desejo do que uma realidade, mesmo em países desenvolvidos. Embora seja um caminho importante, ela não se apresenta sem riscos e contradições. A autonomia de escolha do caminho pedagógico envolve a responsabilidade do resultado. No entanto, o resultado do trabalho docente não é uma variável completamente controlável. Nesse aspecto, a profissão docente transita no universo de uma "responsabilidade limitada", tendo em vista as condições sociais e os limites que se impõem. O exercício da docência envolve a interação com alunos distintos entre si, portanto com demandas distintas e que, ao mesmo tempo, precisam alcançar objetivos coletivos com base em padrões gerais previamente definidos (PERISSET BAGNOUD; GATHER THURLER; BARTHASSAT, 2006). 


\section{Profissionalização dos diretores escolares}

No contexto desse debate de inovação, dirigir um estabelecimento também se tornou uma outra profissão. Ela exige combinar uma pedagogia centrada nas necessidades dos alunos, mas que construa conhecimento de alto nível; estimular um clima de confiança e tolerância na equipe, embora a construção coletiva produza o seu contrário: tensões e conflitos; estimular a cooperação, embora ocorram disputas entre disciplinas, conteúdos e ideologias, da mesma forma que questionamentos sobre hábitos e privilégios pessoais. A nova identidade e as novas habilidades do diretor da escola são definidas a partir de um papel que superaria a tradicional administração da escola e caminharia na direção da liderança cooperativa. Isso sugere um envolvimento no cotidiano, um entender e fazer conexões entre professores, alunos, pais e funcionários da escola. Da mesma maneira, a sua ação se faria a partir da reflexão sobre as práticas de ensino, o funcionamento do estabelecimento, a profissionalização dos professores e a orientação da escola como um todo. Contudo, promover a cultura de cooperação se coloca como o seu maior desafio (GATHER THURLER, 1998b). A cooperação seria construída pelo diretor da escola, que trabalharia para obter o envolvimento dos professores, incentivando a equipe, promovendo a visão de conjunto e trabalhando com o princípio da gestão por consenso. O papel da liderança local seria gerenciar a complexidade de um caminho a ser construído, que mantém o foco nos objetivos de longo prazo, durante um percurso feito de acertos e erros (GATHER THURLER, 1998a).

A direção escolar assume o sentido de uma liderança cooperativa. "A liderança cooperativa entende a administração como uma força de transformação cultural e de desenvolvimento da dinâmica da equipe pedagógica" (GATHER THURLER, 1993, tradução nossa). O papel mais importante do diretor é transformar a cultura do estabelecimento. Para a renovação e superação da cultura existente, Gather Thurler (1993) faz algumas indicações: evitar as conclusões tiradas individualmente; começar com coisas pequenas; definir objetivos não muito exigentes; concentrar-se em um objetivo concreto e importante, como o currículo por exemplo; praticar novas atitudes, embora os riscos possam existir, e aprender a antecipar consequências e a desenvolver estratégias de enfrentamento; delegar poder aos colegas; construir uma visão comum para objetivos e processos comuns de mudança; definir os limites da renovação; ter aliados e obter conselhos. 


\section{Conclusão}

Este estudo examinou as produções, do período de 1990 a 2019, sobre inovação educacional, dos pesquisadores do LIFE da Universidade de Genebra. O objetivo era identificar o que foi abordado nessas produções sobre o tema. Tais inovações não são exclusivas de escolas na Suíça francófona, mas participam de um movimento maior alinhado ao debate de organismos internacionais e à luta contra o fracasso escolar pelos países de cultura ocidental. Os pesquisadores abordam as mudanças de forma sistêmica, tendo sido priorizada neste artigo a discussão de dois grandes eixos de inovação identificados: o das práticas e teorias pedagógicas e o da profissionalização de seus profissionais. Operou-se com a intenção não apenas de elencar as inovações, mas articulá-las numa linha de recuo no tempo, enfatizando, o que foi possível nesse momento, qual era a novidade observável por meio das similaridades e diferenças em relação ao que a precedeu, o que permite uma melhor compreensão e caracterização do momento atual.

Desta forma os debates e experiências educacionais colocados em movimento nos anos de 1990 assinalam rupturas em diferentes dimensões. Com relação às práticas e teorias pedagógicas: identifica-se um entendimento que se afasta do uso de um único modelo pedagógico nos processos de ensino. Assim, amplia-se a crítica ao uso de um modelo pedagógico unicista, incentivando o uso de estratégias e metodologias diferenciadas que assegurem a variedade de percursos de aprendizagem aos estudantes. Da mesma maneira, de um modelo de ensino organizado a partir da lógica da seriação anual, de classes homogêneas e ordenada pelo princípio da faixa etária e do nível de aprendizagem, parte-se para a organização curricular com tempos diferentes para a aprendizagem. No que se refere ao agrupamento dos alunos, observa-se a flexibilização das fronteiras das classes e a organização de grupos que atendam a outras lógicas e necessidades de aprendizagens. Quando o foco é o estudante, observa-se que, de um incentivo à participação ativa em experiências que possibilitassem uma melhor compreensão do conhecimento transmitido, levando-o a se integrar e cooperar com os demais estudantes, caminha-se para o incentivo à participação ativa do aluno para que, por meio da cooperação e da integração com os demais estudantes, recomponha os conhecimentos e os transforme num saber-fazer e/ ou os (re)signifique para seus contextos. Em relação ao currículo, da definição de programas pelo sistema de ensino, altera-se para a implementação de flexibilização curricular com a predefinição de objetivos para sua organização, mas oferecendo espaços para escolhas locais. 
Com relação à profissionalização, identifica-se uma tendência que transita de profissionais com pouca autonomia e submetidos às definições de autoridades educacionais para a construção de autonomia e autoridade profissional que os capacite a realizar escolhas e fazer definições. De uma tradição de formação continuada realizada a partir de cursos e treinamentos externos e esporádicos, caminha-se para uma outra, desenvolvida principalmente, mas não exclusivamente, no próprio terreno da prática, por meio da cooperação e integração de todos os profissionais envolvidos.

Concebendo a inovação como o processo de colocar em prática uma ideia, uma invenção e um conhecimento científico, toda inovação envolve dificuldade e esforço em lidar com a tradição e o costume arraigados. Assim, a inovação é compreendida como um processo, e envolve a tensão entre as possibilidades representadas pela invenção e as escolhas coletivas realizadas. Contudo, nem toda inovação é lida com o mesmo grau de reação. É possível identificar que a inovação pode operar em níveis de mudanças mais ou menos complexos. Enquanto há inovações que tocam as estruturas do sistema ou das instituições de ensino, como os modelos ou formas de organização escolares, outras operam no plano de sala de aula, das metodologias e dos materiais didáticos. Enquanto essas últimas buscam alterar as práticas de ensino, as primeiras desejam modificar as estruturas em que estas se desenvolvem.

As reflexões aqui realizadas exploraram os conhecimentos sobre inovação educacional desenvolvidos pelo LIFE. Ampliar o escopo para outras universidades e laboratórios de pesquisas dos cantões suíços de língua francesa seria interessante para explorar não apenas os resultados e abordagens de outras realidades, mas permitiria uma análise mais segura na observação de regularidades ou não nas estratégias e soluções pensadas por diferentes contextos. Da mesma maneira, a comparação entre países também é um importante recurso de observação e, fundamentalmente, de identificação e compreensão das diferentes apropriações e usos realizados por povos e suas culturas de políticas e paradigmas transnacionais. 


\section{REFERÊNCIAS}

ALTER, Norbert. L'innovation ordinaire. 3e éd. Paris: Quadrige - PUF, 2010.

BARDIN, Laurence. Análise de conteúdo. Tradução de Luís Antero Reta e Augusto Pinheiro. Lisboa: Edições 70, 1977.

BAUMAN, Zygmunt. Modernidade líquida. Rio de Janeiro: Jorge Zahar, 2001.

CROS, Françoise. L'innovation en éducation et en formation. Revue Française de Pédagogie, Lyon, v. 118, p. 127-156, 1997.

GATHER THURLER, Monica. Renouveau pédagogique et responsabilités de la direction de l'établissement. In: COLLOQUE LE DIRECTEUR, LA DIRECTRICE D'ÉTABLISSEMENT SCOLAIRE ET LE RENOUVEAU PÉDAGOGIQUE, 1992, Coppet, Suisse. Actes [...]. Morges, Suisse: AFIDES, 1993. Disponível em: http://www. unige.ch/fapse/SSE/teachers/gather-thurler/Textes/Textes 1993/MGT-1993-03.html. Acesso em: 15 out. 2019.

GATHER THURLER, Monica. Innovation et coopération entre enseignants: liens et limites. In: BONAMI, Michel; GARANT, Michèle (dir.). Systèmes scolaires et pilotage de l'innovation : émergence et implantation du changement. Bruxelles: De Boeck, 1996. p. 145-168.

GATHER THURLER, Monica. La rénovation de l'enseignement primaire à Genève : vers un autre modèle de changement. Premières expériences et perspectives. In: CROS, Françoise (dir.). Dynamiques du changement en éducation et en formation: considérations plurielles sur l'innovation. Paris: INRP/IUFM, 1998a. p. 229-258. (Collection Horizons pour la Formation).

GATHER THURLER, Monica. Savoirs d'action, savoirs d'innovation des chefs d'établissement. In: PELLETIER, Guy (dir.). Former les dirigeants de l'éducation: apprentissage dans l'action. Bruxelles: De Boeck, 1998b. p. 101-131.

GATHER THURLER, Monica. L'innovation négociée: une porte étroite. Revue Française de Pédagogie, Lyon, v. 130, p. 29-42, 2000.

GATHER THURLER, Monica. Stratégies d 'innovation et place des acteurs. In: BRONCKART, Jean-Paul; GATHER THURLER, Monica (ed.). Transformer l'école. Louvain-la-Neuve, Belgique: De Boeck Supérieur, 2004. p. 99-125.

GODIN, Benoît. Innovation: A Conceptual History of an Anonymous Concept. Project on the Intellectual History of Innovation. Working Paper n. 21. Montréal, Québec, 2015. Disponível em: http://www.csiic.ca/PDF/WorkingPaper21.pdf. Acesso em: 15 out. 2019.

HERÁCLITO. Fragmentos. In: OS PRÉ-SOCRÁTICOS. Tradução de José Cavalcanti de Souza et al. São Paulo: Abril, 1989. (Coleção Os Pensadores). 
LI, Ting; MAULINI, Olivier. Vertu en Orient, vice en Occident? Les deux faces de la créativité dans la formation des élèves et les pratiques des enseignants. Formation et Pratiques d'Enseignement en Questions, Université de Genève, H.s. n. 1, p. 51-62, 2016. Disponível em: https://archive-ouverte.unige.ch/unige:86369. Acesso em: 15 out. 2019.

MAULINI, Olivier. Le paradoxe de l'innovation "Changer l'école": pour éloigner ou rapprocher les familles? Educateur, Martigny, n. 5, p. 12-15, 1997.

MAULINI, Olivier. Généraliser la pédagogie différenciée: un paradoxe et un défi pour les institutions scolaires. L'exemple de la rénovation de l'école primaire genevoise. In: COLLOQUE DIVERSITÉ ET DIFFÉRENCIATION EN PÉDAGOGIE, 1999, Lisbonne, Portugal. Conference presentation. Genève: Université de Genève, Faculté de psychologie et des sciences de l'éducation, 2000. Table ronde Différenciation, curriculum et pratiques éducatives.. Disponível em: https://archive-ouverte.unige.ch/unige:41214. Acesso em: 15 out. 2019.

MAULINI, Olivier. La scolarisation des technologies: questionnement didactique, questionnement pédagogique. Genève: Université de Genève, Faculté de Psychologie et Des Sciences de l'Éducation, 2002. Disponível em: https://archive-ouverte.unige.ch/ unige:41108. Acesso em: 15 out. 2019.

MAULINI, Olivier. Un enjeu invisible de l'innovation pédagogique: l'institution du questionnement. In: BRONCKART, Jean-Paul; GATHER THURLER, Monica (ed.). Transformer l'école. Bruxelles: De Boeck, 2004. p. 127-146. (Raisons Éducatives).

MAULINI, Olivier. Différencier pour inclure? L'organisation du travail scolaire en question. Genève: Université de Genève, Faculté de Psychologie et Des Sciences de l'Éducation, 2014. Disponível em: https://archive-ouverte.unige.ch/unige:85548. Acesso em: 15 out. 2019.

MAULINI, Olivier. Que penser... de l'école numérique? Genève: Université de Genève, Faculté de Psychologie et Des Sciences de l'Éducation, 2017. Disponível em: https:// archive-ouverte.unige.ch/unige:109218. Acesso em: 15 out. 2019.

MAULINI, Olivier; PERRENOUD, Philippe. La forme scolaire de l'éducation de base: tensions internes et évolutions. In: MAULINI, Olivier; MONTANDON, Cléopâtre (ed.). Les formes de l'éducation: variété et variations. Bruxelles: De Boeck, 2005. p. 147-168. (Raisons Éducatives).

PERISSET BAGNOUD, Danièle; GATHER THURLER, Monica; BARTHASSAT, Marie-Ange. De l'obligation de résultats aux résultats de l'obligation: de nouveaux paradigmes pour de nouveaux paradoxes. In: AUDIGIER, François; CRAHAY, Marcel; DOLZ, Joaquim (ed.). Curriculum, enseignement et pilotage. Louvain-la-Neuve, Belgique: De Boeck Supérieur, 2006. p. 231-248.

PERRENOUD, Philippe. Du soutien pédagogique à une vraie différenciation de l'enseignement : évolution ou rupture ? Genève: Université de Genève, Faculté de 
Psychologie et Des Sciences de l'Éducation, 1991. Disponível em: https://www.unige. ch/fapse/SSE/teachers/perrenoud/php_main/php_1991/1991_16.html. Acesso em: 15 out. 2019.

PERRENOUD, Philippe. Questions pour une rénovation. Vers Le Changement... Espoirs et Craintes. In: PREMIER FORUM SUR LA RENOVATION DE L'ENSEIGNEMENT PRIMAIRE, 1995, Genéve. Actes [...]. Genève: Département de l'Instruction Publique, 1995. p. 101-108.

PERRENOUD, Philippe. Le métier d'enseignant entre prolétarisation et professionnalisation: deux modèles du changement. Perspectives, Paris, v. 26, n. 3, p. 543-562, 1996.

PERRENOUD, Philippe. Les cycles d'apprentissage : de nouveaux espaces-temps de formation. Educateur, Martigny, n. 14, p. 23-29, déc. 1998.

PERRENOUD, Philippe. De la gestion individuelle d'une classe à la gestion collective d'un cycle d'apprentissage pluriannuel: une nouvelle corde à l'arc des enseignants. Genève: Université de Genève, Faculté de Psychologie et Des Sciences de l'Éducation, 1999. Disponível em: http://www.unige.ch/fapse/SSE/teachers/perrenoud/php_main/ php_1999/1999_06.html. Acesso em: 15 out. 2019.

PERRENOUD, Philippe. Dez novas competências para uma nova profissão. Pátio: Revista Pedagógica, Porto Alegre, n. 17, p. 8-12, maio/jul. 2001.

PERRENOUD, Philippe. Négocier l'orientation, les conditions et le rythme du changement, une culture à construire. Genève: Université de Genève, Faculté de Psychologie et Des Sciences de l'Éducation, 2002. Disponível em: http://www.unige. ch/fapse/SSE/teachers/perrenoud/php_main/php_2002/2002_20.html. Acesso em: 15 out. 2019.

RICOEUR, Paul. Será a crise um fenómeno especificamente moderno ? Revue de Théologie et de Philosophie, [s.l.], v. 120, p. 1-17, 1988. Disponível em: https://www. uc.pt/fluc/uidief/textos_ricoeur/crise_fenomeno_moderno. Acesso em: 14 nov. 2019.

ROSA, Hartmut. Accélération: une critique sociale du temps. Traduit de l'allemand par Didier Renault. Paris: Éditions La Découverte, 2010.

WANDFLUH, Frédérique; MAULINI, Olivier. Lutte contre l'échec et nouvelles formes de travail scolaire: le cas d'un établissement de la banlieue genevoise. Recherches en Éducation, Nantes, n. 10, p. 92-104, 2011.

Texto recebido em 14/01/2021.

Texto aprovado em 08/05/2021. 